\title{
Correlation Analysis between Gender and Different Anxiety Dimension and CET4 Scores
}

\author{
Yongyan Song \\ School of Foreign Languages, Jilin Agricultural University, Changchun 130118, China \\ Email: 1012932249@qq.com
}

Keywords: Correlation analysis; Gender; Anxiety dimension; CET4 scores; Enlightenment

\begin{abstract}
In order to understand the relationship between gender and different anxiety dimension of foreign language learning, CET4 total scores and the scores of the three skills (listening, reading and writing), a random sample of 196 sophomores were investigated on each anxiety dimension of foreign language learning by using the foreign language classroom anxiety scale (FLCAS). Correlation analysis was made by using SPSS software package to analyze the data of each anxiety dimension, CET4 total scores and the scores of the three skills (listening, reading and writing) which are obtained from CET4 of the students in grade 2014 in Jun. 2016. The results indicate that there is no significant difference between gender and each anxiety dimension, however, there is significant difference between gender and CET4 total scores and the scores of the three skills ( listening, reading and writing). Based on this research results, this paper offers the enlightenment on foreign language teaching.
\end{abstract}

\section{Introduction}

Anxiety, as one of the personality characteristics, reflects a state of mental tension caused by inside and outside factors. Anxiety can be divided into trait anxiety, state anxiety and situation-specific anxiety. Foreign language learning anxiety belongs to situation-specific anxiety because it is the anxiety that foreign language learners have in the special occasion of foreign language learning[1]. Over the years, foreign language learning anxiety has always been concerned by many experts and scholars both at home and abroad. Foreign language learning anxiety, as one of the emotional factors, its level is related with the learners' gender and differences of anxiety levels in gender present their features in different stages of learning, which reflects the influence of the differences of gender, personality type and the language proficiency on foreign language learning anxiety[2]. Scholars have done some researches on the relationship between gender and language learning anxiety and the relationship between gender and foreign language learning achievements. They have drawn their own conclusions. For example, Zhang Yonghong has done the research on the relationship between students' foreign language learning anxiety and professional, personality and gender. The result indicates that there is no significant difference between boy students' foreign language learning anxiety level and girl students'[3]. Gao Xianli has done the research on the teachers' attitude, gender differences and foreign language anxiety and middle school students' foreign language learning, the subjects were 60 junior high school students of grade three. The result indicates that there is significant negative correlation between English learning anxiety and gender differences for all relevant tests; teachers' attitude to middle school students' English learning anxiety has obvious predictive effect[4]. Bacon has done research on gender and foreign language learning anxiety and mainly focused on different learning strategies used by boy students and girl students. The result indicates that girl students use met cognitive strategies more easily than boy students[5]. In Clarck \& Trafford's research, they found that girl students tended to do easy tasks and encourage greater motivation while boy students liked challenges and they didn't attach more importance to foreign language learning achievements than girl students[6]. However, there are not many researchers who have done researches on the relationship between gender and anxiety dimensions and CET4 scores. Therefore, this research mainly focuses on the relationship between gender and different anxiety dimension of foreign language learning and CET4 scores. Based on the 
research result, this paper offers the enlightenment on foreign language teaching to reduce foreign language anxiety, which helps improve foreign language teaching quality.

\section{Research Design}

Research Purpose. The purpose of this research is to investigate the relationship between gender and different anxiety dimensions and the relationship between gender and CET 4 total scores and the scores of the three skills (listening, reading and writing), then to analyze the causes of the relationship and offer the enlightenment on foreign language teaching to reduce foreign language learning anxiety, aiming at offering enlightenment for foreign language teaching reform and improving the quality of foreign language teaching.

Research Subject. The research subjects were randomly selected from the students in grade 2014. They were from different disciplines (art and science), different sources (city and countryside) and different genders (male and female). The total number of the subjects are 196. The natural situation of the subjects are as follows, see table 1.

Table 1. Natural situation of the subjects

\begin{tabular}{ccccccc}
\hline \multirow{2}{*}{ Item } & \multicolumn{2}{c}{ Gender } & \multicolumn{3}{c}{ Discipline } & Source \\
\cline { 2 - 7 } & Male & Female & Science & Art & City & Countryside \\
\hline $\mathrm{N}$ & 104 & 92 & 94 & 102 & 96 & 100 \\
Proportion $(\%)$ & 53.06 & 46.94 & 47.96 & 52.04 & 48.98 & 51.02 \\
\hline
\end{tabular}

Research Tool. The tools used in this research are a questionnaire and SPSS software package. The questionnaire includes Horwitz' FLCAS and the natural situation of the subjects. FLCAS contains 33 questions and there are five choices in each question for the subjects to choose, they are very agree, agree, neutral, disagree, very disagree, which respectively presents different anxiety degree. The highest score is 165 and the lowest score is 33. SPSS software package is used to analyze the investigation data and CET4 total scores and the scores of the three skills (listening, reading and writing).

Data Collection. The teachers doing the research explained to the subjects that the purpose of the study was to improve the teaching method and mode and improve the classroom teaching effect and quality. There was no right or wrong for the choice and the data of the investigation was kept secret. Therefore, all the subjects cooperated actively and answered the questions carefully. A total of 200 questionnaires were delivered, 4 of them were eliminated, and 196 of them were valid, the effective rate was $98 \%$.

\section{Result and Analysis}

Correlation Analysis between Gender and Anxiety Dimension. The questions in Horwitz's FLCAS are divided into four anxiety dimensions according to the contents of the questions: communication apprehension, test anxiety, fear of negative evaluation and classroom environment anxiety. The results of correlation analysis between gender and anxiety dimension are as follows, see table 2.

Table 2. Correlation analysis between gender and anxiety dimension

\begin{tabular}{ccccccc}
\hline Item & Gender & $\mathrm{N}$ & Mean & Std. Deviation & $\mathrm{t}$ & Sig. (2-tailed) \\
\hline Communication & Male & 104 & 3.0824 & 0.59743 & -0.237 & 0.813 \\
apprehension & Female & 92 & 3.1025 & 0.58513 & & \\
Test anxiety & Male & 104 & 2.8423 & 0.65280 & 0.082 & 0.082 \\
& Female & 92 & 2.8348 & 0.62940 & & \\
Fear of negative & Male & 104 & 2.7885 & 0.65646 & -0.412 & 0.681 \\
evaluation & Female & 92 & 2.8261 & 0.61570 & & \multirow{2}{*}{0.990} \\
Classroom & Male & 104 & 2.8293 & 0.45306 & -0.013 & \\
environment & female & 92 & 2.8302 & 0.48015 & & \\
anxiety & & & & & & \\
\hline
\end{tabular}


Note: $* \mathrm{p}<0.05, * * \mathrm{p}<0.01, * * * \mathrm{p}<0.001$

It can be seen from table 2, there are differences in anxiety levels between genders in different anxiety dimensions, only in the dimension of test anxiety, the anxiety degree of male students is higher than that of female students, and in other three anxiety dimensions, the anxiety degree of female students is higher than that of male students. However, the independent sample $t$ test showed that there were no significant differences in the four anxiety dimensions of communication apprehension, test anxiety, fear of negative evaluation and classroom environment anxiety $(\mathrm{t}=$ $-0.237, \mathrm{p}=0.813 ; \mathrm{t}=0.082, \mathrm{p}=0.935 ; \mathrm{t}=-0.412, \mathrm{p}=0.681 ; \mathrm{t}=-0.013, \mathrm{p}=0.990)$.

Correlation Analysis between Gender and CET4 scores. The results of correlation analysis between gender and CET4 scores are as follows, see table 3.

Table 3 Correlation analysis between gender and CET4 scores

\begin{tabular}{ccccccc}
\hline Item & Gender & $\mathrm{N}$ & Mean & Std. Deviation & $\mathrm{t}$ & Sig. (2-tailed) \\
\hline CET4 & male & 104 & 365.73 & 43.774 & $-2.899^{* *}$ & 0.004 \\
total & female & 92 & 383.76 & 43.092 & & \\
scores & & & & & & \\
Listening & male & 104 & 118.52 & 19.133 & $-1.978^{*}$ & 0.049 \\
scores & female & 92 & 124.17 & 20.895 & & \\
Reading & male & 104 & 127.71 & 24.796 & $-2.236^{*}$ & 0.027 \\
scores & female & 92 & 135.37 & 22.916 & & \multirow{2}{*}{0.026} \\
Writing & male & 104 & 119.50 & 16.533 & $-2.245^{*}$ & \\
scores & female & 92 & 124.22 & 12.822 & & \\
\hline
\end{tabular}

Note: $* \mathrm{p}<0.05, \quad * * \mathrm{p}<0.01, * * * \mathrm{p}<0.001$

It can be seen from table 3, for CET4 total scores, the average score of female students is 18.03 points higher than that of male students, and there is very significant difference between male and female students in CET4 total scores $(\mathrm{t}=-2.899, \mathrm{p}=0.004)$. For listening scores, the average score of female students is 5.65 points higher than that of male students and there is significant difference between male and female students in listening scores $(t=-1.978, p=0.049)$. For reading scores, the average score of female students is 7.66 points higher than that of male students and there is significant difference between male and female students in reading scores $(t=-2.236, p=0.027)$. For writing scores, the average score of female students is 4.72 points higher than that of male students and there is significant difference between male and female students in writing scores $(\mathrm{t}=-2.245$, $\mathrm{p}=0.026$ ).

\section{Conclusion and Enlightenment}

Conclusion. The above results show that there is no significant difference between the gender and the anxiety degree of each dimension, which is consistent with the findings of Cheng Yanping, He Qiguang and Han Xiaoli, that is there is no significant difference between male and female students in communication apprehension, test anxiety, fear of negative evaluation and classroom environment anxiety[7]. There are very significant differences between gender and CET 4 total scores and there are significant differences between the gender and listening scores, reading scores and writing scores, which is consistent with the findings of Shi Yunzhang and Liu Zhenqian's study of the relationship between gender and reading scores, that is the reading scores of female students is higher than that of male students, and there is significant difference between them[8].The results of this research are also consistent with that of Yuan Fengshi and Xiao Defan' research on gender differences in English classroom behaviors and the relationship between the behaviors and CET4 scores, which indicated that there were certain gender differences of the relationships between the behaviors and CET4 scores.[9]

Enlightenment. This research enriches the study of the relationship between gender and foreign language learning anxiety and academic achievement, and also has some enlightenment for foreign language teaching. As college English teachers, we should teach students in accordance with their aptitude according to the differences between male students and female students in college English 
classroom teaching, choose appropriate listening, reading and writing materials, and strive to create a relaxed and enjoyable learning environment for students to experience success, gain self-confidence and enhance students' learning motivation and interest as much as possible in learning English so as to improve the quality of foreign language teaching because relaxed and pleasant learning environment can reduce students' learning anxiety, and thus improving their foreign language learning achievement [10].

\section{References}

[1] W.H. Huo: Study on the Gender Differences of Foreign Language Learning Anxiety in Twenty-first Century[J]. Modern Education Management, (2009) No 5, p. 66-68. (in Chinese).

[2] H. Lin: On the Influence of Learners' Sex on Foreign Language Anxiety in Different Learning Stages[J]. Journal of Hanshan Normal University, Vol. 29 (2008 ) No. 1, p. 94-97. (in Chinese).

[3] Y. H. Zhang: On the Relationship between Students' Foreign Language Learning Anxiety and Professional, Personality and Gender[J].The Guide of Science \& Education, (2014) No. 2, p. 187-188. (in Chinese).

[4] X. L. Gao: Teacher Attitudes, Gender Differences, Foreign Language Anxiety and Middle School Students' Foreign Language Learning[J]. Journal of Inner Mongolia Normal University (Educational Science ), Vol. 24 (2011) No. 6, p. 45-48. (In Chinese).

[5] S.M. Bacon: The Relationship between Gender, Comprehension, Processing Strategies and Cognitive and Affective Response in Foreign Language Listening [J]. The Modern Language Journal, Vol. 76 (1992) No. 2, p. 160-178.

[6] A. Clarck, and J. Trafford: Return to gender : boys' and girls' attitudes and achievements[J]. Language Learning Journal, (1996) No.14, p. 40-49.

[7] Y.P. Cheng, Q.G. He and X.L. Han: The Effect of English Classroom Anxiety on College Students Oral Performance[J]. Language Teaching and Linguistic Studies, (2007) No.1, p. 89-94. (in Chinese).

[8] Y.Z. Shi and Z.Q. Liu: Foreign Language Reading Anxiety and Its Relationship to English Achievement and Gender[J]. Journal of PLA University of Foreign Languages, Vol 29 (2006) No. 2, p. 59-64. (in Chinese).

[9] F.S. Yuan and D.F. Xiao: Research on Gender Differences in English Classroom Behaviors and the Relationship between the Behaviors and CET4 Scores[J]. Foreign Languages and Their Teaching, (2003) No. 8, p. 22-25. (in Chinese).

[10] D. J. Young: Creating a Low-anxiety Classroom Environment: What Does Language Anxiety Research Suggest? [J]. The Modern Language Journal. Vol. 75 (1991) No. 4, p. 426-437. 